\title{
Development of thermal bridge numerical model, based on conjugate heat transfer and indoor and outdoor environment parameters
}

\author{
Martin Ivanov $^{1^{*}}$, Sergey Mijorski ${ }^{2}$ \\ ${ }^{1}$ Technical University - Sofia, FPEPM, Department:" Hydroaerodynamics and Hydraulic Machines", \\ Sofia 1000, Bulgaria \\ ${ }^{2}$ SoftSim Consult Ltd., Consultant at Technical University of Sofia, FPEPM, Department:" \\ Hydroaerodynamics and Hydraulic Machines", Sofia 1000, Bulgaria
}

\begin{abstract}
The presented study reveals the development of a 3D numerical model for thermal bridge assessment, based on conjugate heat transfer and CFD methods. With the developed model, thermal simulations are performed, in order to analyse the interaction between different ambient conditions and material properties. The results show that the wall boundary layer profiles are depended on the attached air flow velocity magnitude and implemented wall roughness. The parametric analysis, of the varying ambient air temperatures, confirm the linear dependence to the internal wall surface temperatures. The demonstrated correlations, in regard of the attached air flow velocity magnitude and wall roughness heights, are nonlinear. The most characteristic result, achieved in the simulation study, is the impact of the wall roughness, over the internal wall temperature. The increase of the roughness leads to significant increase of the internal wall temperature. Explanation may be found in the boundary layer flow velocity magnitude near the external wall, which decreases the heat energy transfer between the solid and cold fluid medias.
\end{abstract}

\section{Introduction}

In today's building sector, thermal bridges calculation is addressed in the construction guidelines, in most of the European countries [1]. Throughout the building design, it is recommended to avoid thermal bridges, and this is the usual practise, prescribed in different norms and standards. [2,3] Such technical documents give the required ambient and material parameters for thermal bridge analyses, based on long term building experience and practical studies in this area. It is very important to perform these analyses, because the linear thermal bridges may rise the heating energy requirement of the buildings with above $30 \%$. [4] It is hard to estimate the total impact of the thermal bridges, over the energy demand of the buildings, but it may vary from few percent in old non-restored buildings, up to almost $40 \%$ in new, heavily isolated constructions, with non-covered thermal bridge areas. [5, 6] Modern facades, like double-skin, cladding systems or smart and ventilated

\footnotetext{
* Corresponding author: $\underline{\mathrm{m} \text { ivanov@tu-sofia.bg }}$
} 
facades, rise the demand for more energy efficient building envelope technologies, and hence require significant reduction in the thermal bridge appearance prerequisites. [7]

However, thermal bridges still exist worldwide, particularly in older buildings, where no energy efficiency procedures or retrofits have been applied. In such premises, the thermal bridges may have significant impact over the indoor air quality as well. In winter conditions for example, excess moisture accumulation may appear over the cold spot regions. These moisture related problems and the consequent mould growth are strongly related to important health outcomes in occupants, like advent of allergies and even asthma. Thus, analyses of the generic conditions for thermal bridge appearance is important issue for the presented area. $[8,9]$

Numerical modelling of the described above phenomena is generally not an easy task, though it does help the thermal bridge avoidance in the building design process. The calculation of the steady-state temperature in the affected zones could be performed by standard finite element or temperature method, and by statically admissible flow method. [10] But, the dynamic modelling of the thermal bridges reduces the underestimation of their effect on the building performance, which is normally made by the analytical U-value method and the equivalent wall method. [11] However, the modelling methods, based on the Computational fluid dynamics (CFD), require significant modelling skills and precisely implemented initial and boundary conditions. Sometimes, the flow past complex geometries is hard to discretize, and the thermal bridges normally appear in complex junctions, between different building elements. [12]

Consequently, the development of accurate, multiparametric 3D numerical models for thermal bridge analyses, will support the buildings design practice. The presented paper suggests such primary model, based on conjugated heat transfer and CFD methods. Thermal transmittance through concrete wall is simulated, and the effect of the ambient flow conditions is analysed.

The objective of the study is to develop a 3D numerical model for thermal bridge assessment, through the means of the CFD methods and conjugate heat transfer, and to analyse different indoor, outdoor and material parameters, affecting this phenomenon.

\section{Numerical model}

For purpose of the study, a simplified geometry of exterior building wall is constructed, and presented on Fig. 1. The 3D model encompasses a wall section with dimensions $4 \mathrm{~m}$ by $4 \mathrm{~m}$, including two fluid (air) and one solid regions. The test section used for the analysis is with dimensions $1 \mathrm{~m}$ by $1 \mathrm{~m}$ and wall thickness of $0.2 \mathrm{~m}$. The material used for the solid region is a concrete with density of $2400 \mathrm{~kg} / \mathrm{m}^{3}$, specific heat of $750 \mathrm{~J} /(\mathrm{kg} \mathrm{K})$, and thermal conductivity of $1.8 \mathrm{~W} /(\mathrm{m} \mathrm{K})$.

Numerical discretisation is completed with snappyHexMesh meshing utility within OpenFoam ${ }^{\circledR}$, creating a hexahedral and polyhedral mesh of 485608 control volume cells. Each of the wall surfaces within the computational domain is with 5 prism layers projecting toward inlets and outlets of the fluid regions and first layer height is $0.005 \mathrm{~m}$ (see Fig.1). The selected base cell size of the computational domain is based on a completed grid sensitivity study. The results of this supplementary analyses are shown on Fig. 2 and Fig. 3, in terms of surface temperatures and heat flux distribution for different base cell sizes. Three different grid sizes are tested, and four different parameters are analysed: minimum, mean, and maximum surface temperatures and resultant heat flux between the solid and internal fluid regions. Thus, an optimum mesh size of $0.05 \mathrm{~m}$ was considered, as there is no statistically meaningful difference for the resulting monitored parameters. 


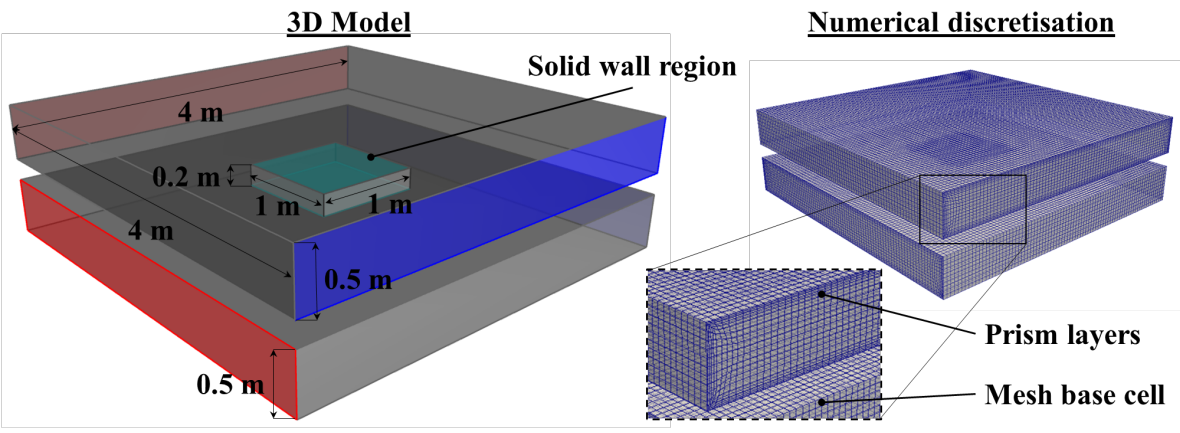

Fig. 1. 3D model and numerical discretisation

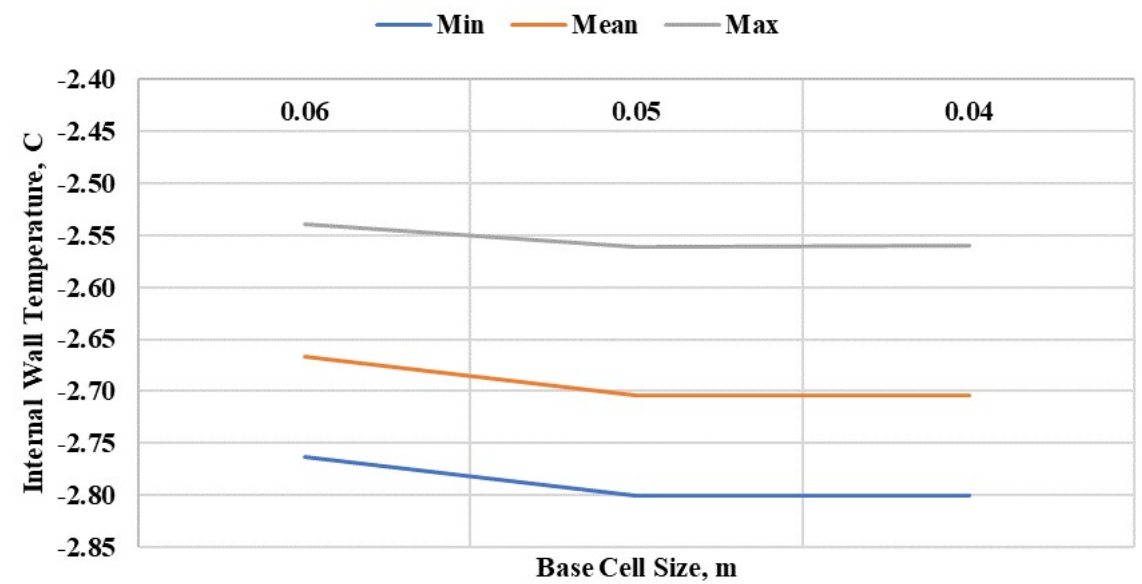

Fig. 2. Grid sensitivity - surface temperatures comparison

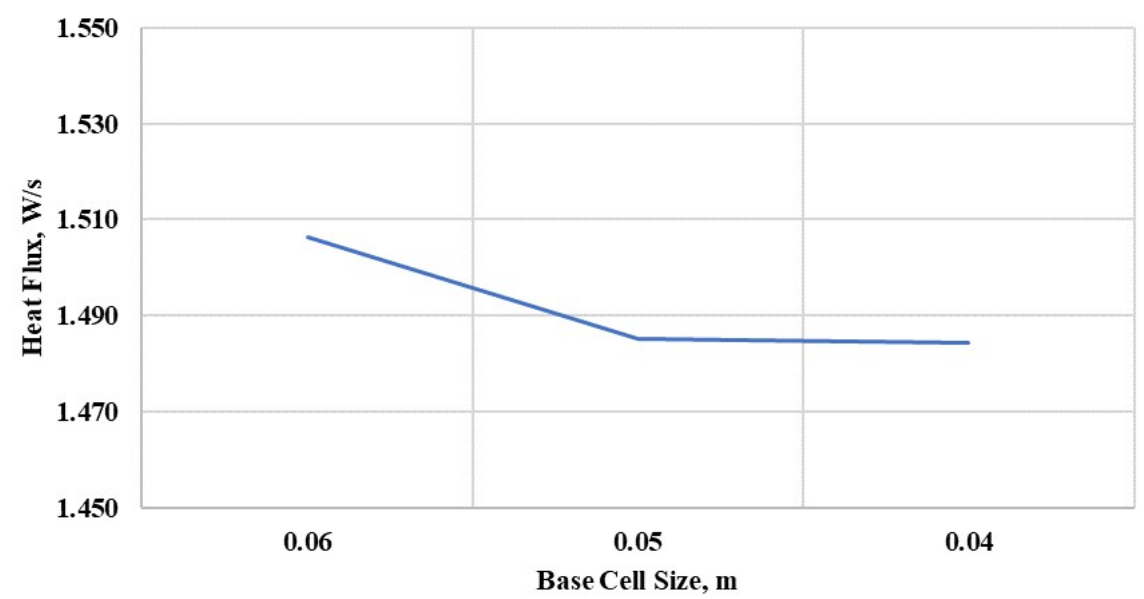

Fig. 3. Grid sensitivity - surface heat flux comparison 


\section{Simulations set-up and scenarios}

In total, 15 steady state conjugate heat transfer simulations are performed with use of Realisable k-epsilon turbulence model and standard wall function within the CFD software Ansys Fluent 16.0. For the purposes of the analysis a constant indoor environment conditions are modelled with air temperature of $24{ }^{\circ} \mathrm{C}$. This is accomplished by providing constant air flow along the interior of the test section with uniform velocity of $0.1 \mathrm{~m} / \mathrm{s}$, parallel to the wall. This way the impact of the different parameters (ambient conditions and wall surface and material properties) over the interior surface temperature could be compared and analysed. The outdoor environment parameters are modelled with varying air flow intensity parallel to the exterior of the test section. The configuration is tested for different external air temperatures from $-20{ }^{\circ} \mathrm{C}$ to $10{ }^{\circ} \mathrm{C}$, wall roughness heights in the range of $0.3 \mathrm{~mm}$ to $5.0 \mathrm{~mm}$ and different flow speeds - from $0.5 \mathrm{~m} / \mathrm{s}$ to $3 \mathrm{~m} / \mathrm{s}$. The specified CFD model boundary conditions are outlined on Fig. 4.

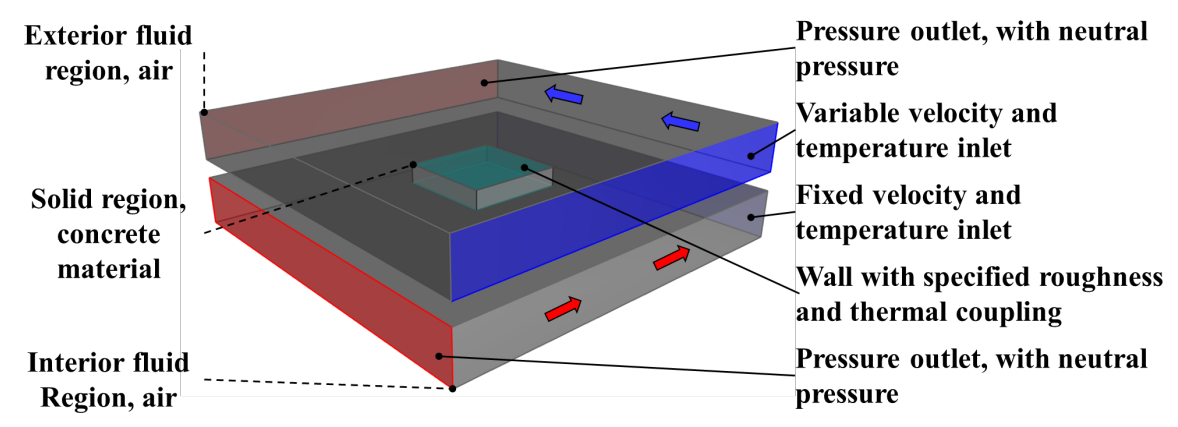

Fig. 4. CFD model boundary conditions

The standard wall function, implemented within the Fluent software, is proposed by Launder and Spalding. [13] The calculation of the momentum at the wall boundary is completed by law-of-the-wall for mean velocity as follows:

$$
U^{*}=\frac{1}{\kappa} \ln \left(E y^{*}\right)
$$

where:

$$
U^{*}=\frac{U_{P} C_{\mu}^{1 / 4} k_{P}^{1 / 2}}{\tau_{w} / \rho} \text { and } y^{*}=\frac{\rho C_{\mu}^{1 / 4} k_{P}^{1 / 2} y_{P}}{\mu}
$$

$U^{*}$ - dimensionless velocity

$y^{*}$ - dimensionless distance from the wall

$\kappa$ - von Kármán constant, 0.4187

$C \mu$ - empirical constant, 0.09

$E$ - empirical constant, 9.793

$\tau_{w}$ - is the local wall shear stress

$U_{p}$ - mean velocity of the air flow at given point

$k_{p}$ - turbulence kinetic energy at given point 
$y_{p}$ - distance from the point to the wall surface

$\mu$ - dynamic viscosity of the air

$\rho$ - density of air

When $y^{*}$ value is greater than 11.225 , the logarithmic law for mean velocity is employed, and when is less (within finer mesh regions), it is applied a laminar stress-strain relationship between mean velocity and $y^{*}: U^{*}=y^{*}$. While, the law-of-the-wall for energy modelling comprises two different laws:

- "linear law for the thermal conduction sublayer where conduction is important"

- "logarithmic law for the turbulent region where effects of turbulence dominate conduction".

This way, the law-of-the-wall takes the following form [14]:

$$
T^{*}=\frac{\left(T_{w}-T_{P}\right) \rho c_{p} C_{\mu}^{1 / 4} k_{P}^{1 / 2}}{\dot{q}}=\left\{\begin{array}{cc}
\operatorname{Pr} y^{*}+\frac{1}{2} \rho \operatorname{Pr} \frac{C_{\mu}^{1 / 4} k_{P}^{1 / 2}}{\dot{q}} U_{P}^{2} & y^{*}<y_{T}^{*} \\
\operatorname{Pr}_{t}\left[\frac{1}{k} \ln \left(E y^{*}\right)+P\right]+ & y^{*}>y_{T}^{*} \\
\frac{1}{2} \rho \frac{C_{\mu}^{1 / 4} k_{P}^{1 / 2}}{\dot{q}}\left\{\operatorname{Pr}_{t} U_{P}^{2}+\left(\operatorname{Pr}-\operatorname{Pr}_{t}\right) U_{c}^{2}\right\} &
\end{array}\right\}
$$

where:

$$
P=9.24\left[\left(\frac{P r}{P r_{t}}\right)^{3 / 4}-1\right]\left[1+0.28 e^{-0.007 P r} / P r_{t}\right]
$$

$y_{T}^{*}$ - non-dimensional thermal sublayer thickness

$c_{p}$ - specific heat of the air

$\dot{q}$ - heat flux at the surface

$T_{p}$ - temperature at given point adjacent to surface

$T_{w}$ - surface temperature

$\mathrm{Pr}$ - molecular Prandtl number

$P_{t}$ - turbulent Prandtl number, 0.85 at the surface

$A$ - Van Driest constant, 26

$U_{c}$ - mean velocity magnitude for $y^{*}=y_{T}$.

\section{Results and discussion}

Numerical results in form of temperature and velocity fields through the centre of the computational domain, and parallel to the outdoor air flow for one exterior condition (velocity magnitude of $0.5 \mathrm{~m} / \mathrm{s}$ at $-20{ }^{\circ} \mathrm{C}$ ), are shown on Fig. 5 and Fig. 6. The thermal conductivity in the presented case is $1.8 \mathrm{~W} /(\mathrm{m} \mathrm{K})$, while surface roughness is $0.3 \mathrm{~mm}$.

As illustrated on the velocity and temperature field plots, the wall boundary layer flow would be sensible to the test section positioning and sizing. This way, the resulted profiles along the wall surface could not be fully developed prior to the test section. However, this depends on the wall roughness and modelled attached flow velocity magnitude. Additionally, for capturing more precisely the conjugate heat transfer process, the adjacent construction elements and corresponding thermal properties of the tested buildings should be included. 

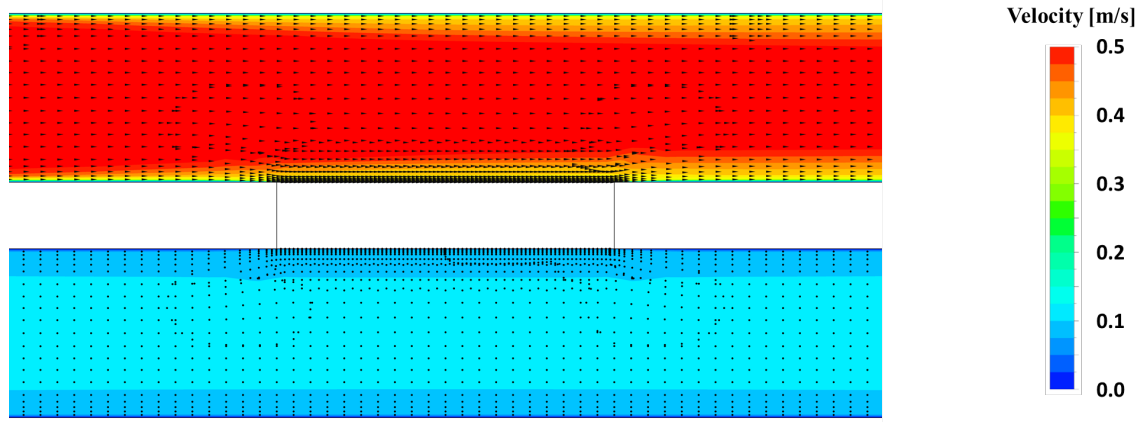

Fig. 5. Velocity field plot
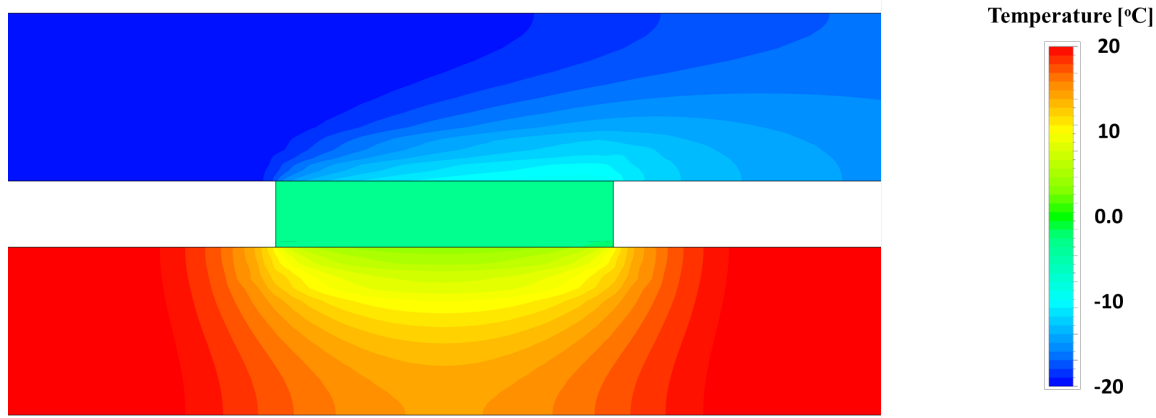

Fig. 6. Temperature field plot

Three different parametric analyses are shown by graphical representations of the mean interior wall temperature of the test section, including:

- external air temperature, presented on Fig. 7;

- external attached air flow velocity magnitude, presented on Fig. 8;

- and wall roughness heights, presented on Fig. 9.

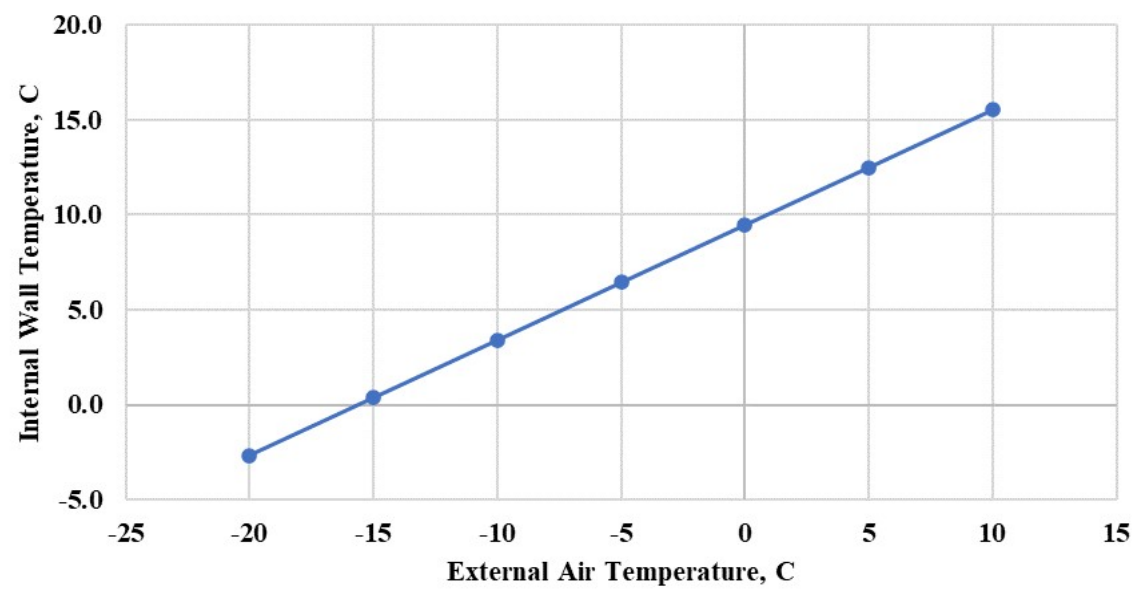

Fig. 7. External air temperature sensitivity analysis 


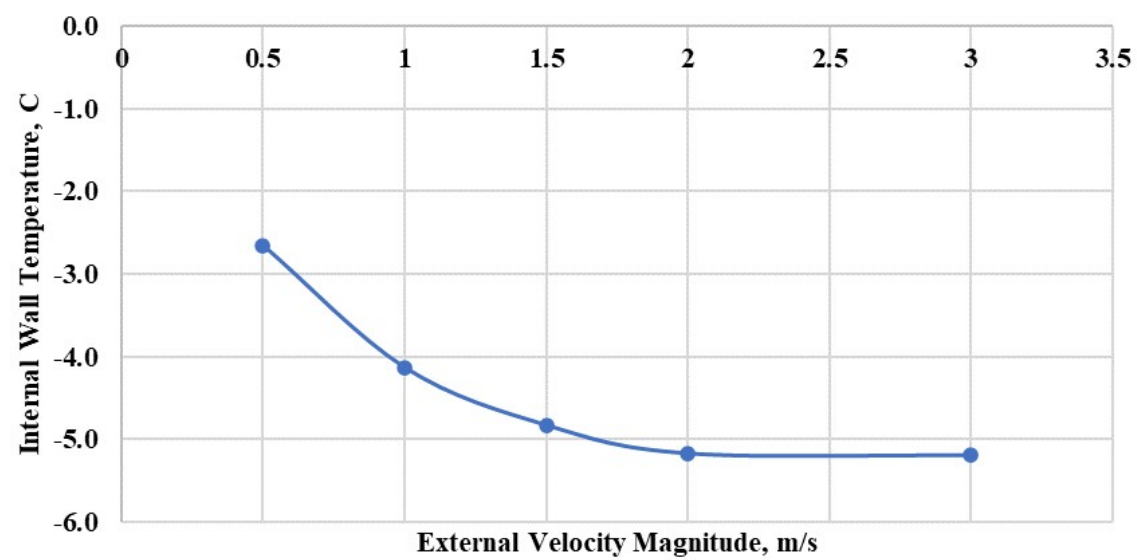

Fig. 8. Attached air flow sensitivity analysis

The parametric analysis of the varying ambient air temperatures shown on Fig. 7 illustrates a linear dependence to the internal wall surface temperatures. While, on Fig. 8 and 9 are demonstrated the non-linear dependencies in regard of the attached air flow velocity magnitude and wall roughness height.

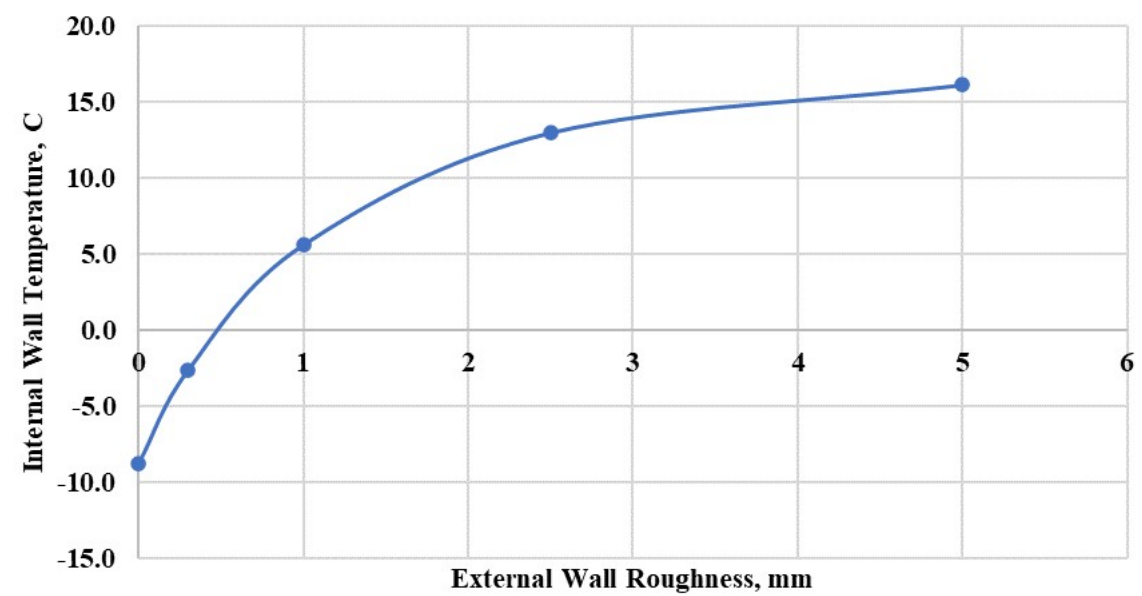

Fig. 9. External wall roughness sensitivity analysis

It is seen that, the increase of the external wall velocity magnitude from $0.5 \mathrm{~m} / \mathrm{s}$ up to 3 $\mathrm{m} / \mathrm{s}$, leads to decrease of the internal wall temperature from $-2.7{ }^{\circ} \mathrm{C}$ to $-5.2{ }^{\circ} \mathrm{C}$. This decrease is attained without changing the flow direction, which might have additional impact over these values. More sensible drop of the interior wall temperature is observed between $0.5 \mathrm{~m} / \mathrm{s}$ and $2.0 \mathrm{~m} / \mathrm{s}$ velocity magnitude. This demonstrate the need of further investigation of the means for impacting attached wind flows along building facades, thus ensuring lower velocity magnitudes within exterior walls boundary layer and lowering building heat losses.

Furthermore, the effect of the wall roughness change shown on Fig. 9 confirms the observed impact of attached flow velocity magnitude. With the increase of roughness height, more sensible is the drop of the heat loss and higher is the interior surface 
temperature. This way with smooth wall, the temperature drops to $-8.8{ }^{\circ} \mathrm{C}$ and with coarsest material ( $5 \mathrm{~mm}$ roughness), reaches almost $16.1{ }^{\circ} \mathrm{C}$.

This effect is explained with the boundary layer flow velocity magnitude near the external wall, which decreases the heat energy transfer between the solid and cold fluid medias. However, this phenomenon would require additional analyses of the turbulence models and applied wall functions. Also, sufficient measurement data is not yet available, in order to validate the presented numerical model.

\section{Conclusions}

In the presented study 3D numerical model for thermal bridge assessment is developed. The model is based on CFD methods and conjugate heat transfer. Model simulations are performed, in order to analyse the interaction between different indoor, outdoor conditions and material properties.

The results show that the wall boundary layer profiles are depended on the attached velocity magnitude and implemented wall roughness. This limits the application of the presented model to the particular length of the wall before test section and points out the need for modelling of the adjacent construction elements with the corresponding thermal properties.

The parametric analysis, of the varying ambient air temperatures, confirm the linear dependence to the internal wall surface temperatures. The demonstrated dependencies, in regard of the attached air flow velocity magnitude and wall roughness heights, are nonlinear.

The results also show that the increase of the external wall velocity from $0.5 \mathrm{~m} / \mathrm{s}$ up to 3 $\mathrm{m} / \mathrm{s}$, leads to decrease of the internal wall temperature from $-2.7{ }^{\circ} \mathrm{C}$ to $-5.2{ }^{\circ} \mathrm{C}$, attained without changing the flow direction. Thus, a need exists for further investigation of the means for impacting attached wind flows along building facades, ensuring lower velocities within exterior walls boundary layer.

The most distinctive observed result is the impact of the wall roughness, over the internal wall temperature. The increase of the roughness leads to significant increase of the internal wall temperature. It is due to the boundary layer flow velocity magnitude near the external wall, which decreases the heat energy transfer between the solid and cold fluid medias.

Future work of the authors would include performing an experimental measurement study for validation of the proposed thermal bridge assessment CFD model. By assessing different environmental conditions and wall material properties to be proven the validity of the proposed 3D numerical method and to outline the advantages when compared with the existing simplified code thermal bridge calculations.

The presented study is supported by the National Science Fund at the Ministry of Education and Science of Bulgaria, under the activities of: "Competition for financial support for projects of junior basic researchers and postdocs - 2018", with Contract № КП-06-M27/4, entitled: "Numerical assessment of effective measures for prevention of moisture accumulation on external walls with thermal bridge, in residential rooms without organized ventilation". 


\section{References}

[1] K. Kussk, J. Kurnitski and T. Kalamees, Calculation and compliance procedures of thermal bridges in energy calculations in various European countries, Energy Proc. J. 132: 27-32, (2017)

[2] A. Papadopoulos, Forty years of regulations on the thermal performance of the building envelope in Europe: achievements, perspectives and challenges, Energy Build. 127, (2016) [3] ISO 10211, Thermal Bridges in Building Construction - Heat Flows and Surface Temperatures. Detailed calculations, Int. Org. for Standardization, (2017)

[4] H. Erhorn-Kluttig, H. Erhorn, Impact of thermal bridges on the energy performance of buildings, Paper P148 of the EPBD Buildings Platform, www.buildup.eu/sites/default/ files/content/P 148 EN_ASIEPI_WP4 IP2.pdf., (2009)

[5] T. Theodosiou, A. Papadopoulos, The impact of thermal bridges on the energy demand of buildings with double brick wall constructions, J. Energy and Build. 40: 2083-2089, Elsevier, doi:10.1016/j.enbuild.2008.06.006, (2008)

[6] K. Martin, A. Erkoreka, I. Flores, M. Odriozola and J.M. Sala, Problems in the calculation of thermal bridges in dynamic conditions, J. Energy and Build. 43: 529-535, Elsevier, doi:10.1016/j.enbuild.2010.10.018, (2011)

[7] T. Theodosiou, K. Tsikaloudaki, S. Tsoka and P. Chastas, Thermal bridging problems on advanced cladding systems and smart building facades, J. of Cleaner Prod. 214: 62-69, Elsevier, doi:10.1016/j.jclepro.2018.12.286, (2019)

[8] M. Ivanov, Instantaneous field measurements of thermal bridge parameters in ground floor residential room, Proc. "8th Int. Conf. on Thermal Equip., Ren. Energy and Rural Dev. - TE-RE-RD 2019”, Web of Conf., doi: 10.1051/e3sconf/201911201016, (2019)

[9] M. Ivanov, Dew point temperature analyses in ground floor residential room with existing thermal bridge, Proc. "8th Int. Conf. on Thermal Equip., Ren. Energy and Rural Dev. - TE-RE-RD 2019”, Web of Conf., doi: 10.1051/e3sconf/201911201017, (2019)

[10] S. Taoum, E. Lefrançois, Dual analysis for heat exchange: Application to thermal bridges, J. Comp. and Math. with App. 75: 3471-3487, Elsevier, (2018)

[11] H. Ge, F. Baba, Effect of dynamic modelling of thermal bridges on the energy performance of residential buildings with high thermal mass for cold climates, J. Sustain. Cities and Soc. 34: 250-263, Elsevier, (2017)

[12] A. Terziev, Specifics in numerical modelling of flow past a square-cylinder, Proc. of Sc. Conf. of Ruse University "Angel Kanchev, vol. 53, book 1.2: 143-149, ISSN 13113321, (2014)

[13] Launder B. E., Spalding D. B., The Numerical Computation of Turbulent Flow, Comp. Methods in Applied Mech. and Eng., 3:269-289, (1974)

[14] Jayatilleke C., The Influence of Prandtl Number and Surface Roughness on the Resistance of the Laminar Sublayer to Momentum and Heat Transfer, Prog. Heat Mass Transfer, 1:193-321, (1969) 